\title{
Insulin signal transduction is impaired in the type 2 diabetic retina
}

\author{
Youde Jiang ${ }^{1}$, Li Liu1, Hainan $\mathrm{Li}^{2}$, Jie-Mei Wang ${ }^{2}$, and Jena J. Steinle ${ }^{1}$ \\ ${ }^{1}$ Department of Ophthalmology, Visual, and Anatomical Sciences, ${ }^{2}$ Department of \\ Pharmaceutical Sciences, Wayne State University, Detroit, MI USA
}

Running Title: Insulin in the $\mathrm{db} / \mathrm{db}$ mouse

Correspondence: Jena J. Steinle, Professor, Department of Ophthalmology, Visual and Anatomical Sciences, 9314 Scott Hall, Detroit, MI 48202. Phone (313) 577-9731; Fax 313-577-

3125; email: jsteinle@med.wayne.edu 
Abstract. Rates of type 2 diabetes are reaching epidemic levels. Yet, the tissue specific alterations due to insulin resistance are only recently being investigated. The goal of the present study was to evaluate retinal insulin signal transduction in a common mouse model of type 2 diabetes, the $\mathrm{db} / \mathrm{db}$ mouse. Retinal lysates from five month old male $\mathrm{db} / \mathrm{db}$ and $\mathrm{db} /+$ (control) mice were collected and processed for Western blotting or ELISA analyses for insulin receptor, insulin receptor substrate-1 (IRS-1), Akt, tumor necrosis factor alpha (TNF $\alpha$ ) and caspase 3 levels. Data demonstrate increased TNF $\alpha$ and IRS-1 phosphorylation on serine 307. This led to decreased Akt phosphorylation on serine 473 and increased cleavage of caspase 3. Taken together, the data suggest dysfunctional insulin signaling in the retina of the $\mathrm{db} / \mathrm{db}$ mouse.

Keywords: $\mathrm{db} / \mathrm{db}$, retina, insulin, TNF $\alpha$, type 2 diabetes 
Introduction. With increasing rates of obesity, rates of type 2 diabetes and diabetic complications are expected to rise exponentially over the next few decades (American Diabetic Association). A key feature of type 2 diabetes is a resistance to insulin. Insulin signaling is key to a number of physiological processes, including glucose metabolism, cell growth, general gene expression, and apoptosis. Studies have focused on insulin resistance in the insulinresponsive tissues with less focus on other organs, such as the retina. We have previously reported that diabetes-induced increases in TNF $\alpha$ can cause phosphorylation of insulin receptor substrate 1 (IRS-1) in Serine 307, thus inhibiting normal insulin signal transduction in retinal endothelial cells [1]. This increase in TNF $\alpha$ was also associated with increased cleavage of caspase 3. We found similar findings in BBZDR/Wor type 2 diabetic rats [2, 3]. However, it was not clear if these findings also occurred in type 2 diabetic mouse models.

For these studies, we used the $\mathrm{db} / \mathrm{db}$ model of type 2 diabetes. We chose to use these mice as others have reported significant retinal changes. Work showed that intermittent fasting altered the gut microbiome in the $\mathrm{db} / \mathrm{db}$ mice, which was associated with less retinal damage [4]. Additional studies also showed that diabetes in the $\mathrm{db} / \mathrm{db}$ mice led to reduced diurnal oscillatory rhythms, which altered metabolic pathways [5]. Other groups reported increased permeability and inflammatory mediators in the retina of $\mathrm{db} / \mathrm{db}$ mice, which was reduced by C1q/tumor necrosis factor (TNF) related protein 9 [6]. Ginsenoside Rg1 was shown to reduce retinal neurodegeneration in the $\mathrm{db} / \mathrm{db}$ mouse through activation of IRS-1/Akt/GSK3 $\beta$ levels [7]. Since it is clear that the retinas of $\mathrm{db} / \mathrm{db}$ mice have damage, we wanted ascertain whether this was due to altered insulin signal transduction.

We hypothesized that retinal lysates from $\mathrm{db} / \mathrm{db}$ mice would have increased IRS-1 Ser307 phosphorylation, leading to decreased Akt levels with increased cleavage of caspase 3. 


\section{Methods:}

Mice. Five month old male db/db (BKS.Cg-Dock7m+/+Lepr ${ }^{\mathrm{db}}$, wildtype for Dock $7^{\mathrm{m}}$, homozygous for Lepr ${ }^{\mathrm{db}}$ ) and db/+ (wildtype for Dock7m, wildtype for Lepr ${ }^{\mathrm{db}}$, from the same colony) mice were used for these experiments. Mice were purchased from Jackson Laboratory (\#000642) at 2 months and age and allowed to age to 5 months at the vivarium. All animal procedures meet the Association for Research in Vision and Ophthalmology requirements and were approved by the Institutional Animal Care and Use Committee of Wayne State University and conform to NIH guidelines. Animal body weights and glucose levels are in Table 1.

Western blotting. Whole retinal lysates were collected into lysis buffer containing protease and phosphatase inhibitors. Equal amounts of protein were placed into pre-cast tris-glycine gels (Invitrogen, Carlsbad, CA), and blotted onto nitrocellulose membranes. After blocking in TBST (10mM Tris- $\mathrm{HCl}$ buffer, $\mathrm{pH} 8.0,150 \mathrm{mM} \mathrm{NaCl}, 0.1 \%$ Tween 20 ) with 5\% BSA, membranes were treated with a phosphorylated insulin receptor (Tyr 1150/1151), insulin receptor, phosphorylated Akt (Ser473), total Akt, phosphorylated insulin receptor substrate 1 (Ser307), total IRS-1 (Cell Signaling Technology, Danvers, MA) TNF $\alpha$, (Abcam, Cambridge, MA), and beta actin (Santa Cruz Biotechnology, Santa Cruz, CA) primary antibodies overnight. The following day, membranes were incubated with secondary antibodies labeled with horseradish peroxidase. Antigen-antibody complexes were visualized using chemilluminescence (Thermo Scientific, Pittsburgh, PA). Data was analyzed on an Azure C500 machine (Azure Biosystems, Dublin, CA). Western blot band densities were measured using Image Studio Lite software.

ELISA. A cleaved caspase 3 ELISA (Cell Signaling Technology, Danvers, MA) was done according to manufacturer's instructions. 
Statistics. Data were assessed for changes $\mathrm{db} /+$ control mice. Data are presented as mean 土SEM. $\quad P<0.05$ was accepted as significant. Data was analyzed using Prism 8.0 (GraphPad software).

\section{Results:}

Diabetes reduces insulin receptor and Akt phosphorylation. As we have shown in the retina from diabetic rats [3], diabetes significantly reduced insulin receptor and Akt phosphorylation in the $\mathrm{db} / \mathrm{db}$ retina (Figure 1).

TNF $\alpha$ and IRS-1Ser307 phosphorylation are increased in the $d b / d b$ retina. With Akt phosphorylation reduced in the retina of $\mathrm{db} / \mathrm{db}$ mice, one possible mechanism is due to increased IRS-1 ${ }^{\text {Ser307 }}$ phosphorylation. We have previously shown that diabetes-induced increases in TNF $\alpha$ can increase IRS-1 ${ }^{\text {Ser307 }}$ phosphorylation in retinal cell types $[1,8]$, which results in dysfunctional insulin signal transduction. Figure 2 shows increased TNF $\alpha$ and IRS$1^{\text {Ser307 }}$ phosphorylation in the retina of $\mathrm{db} / \mathrm{db}$ mice.

Cleaved caspase 3 is increased in the type 2 diabetic retina. With reduced Akt phosphorylation, it follows that cleaved caspase 3 levels are significantly increased in the retina of the $\mathrm{db} / \mathrm{db}$ mice (Figure 3).

Discussion: Type 2 diabetes is characterized by insulin resistance. However, this typically applies to insulin-responsive tissues, such as muscle, adipose tissue, and the liver. We have previously reported altered insulin receptor signaling in toll-like receptor 4 knockout mice [9], miR15a mice [10], and in retinal endothelial cells [1] and Müller cells [8]. However, none of these models mimic type 2 diabetes. We have shown retina damage in the type 2 diabetic rat 
model, the BBZDR/Wor rat $[2,3]$. In this study, we wanted to investigate insulin signal transduction in the retina of $\mathrm{db} / \mathrm{db}$ mice.

Studies on jejunal proteins from db/db mice showed impaired muscle insulin signaling, leading to insulin resistance [11]. Work has shown that rexinoids improved insulin signaling in skeletal muscle through decreased IRS-1 ${ }^{\text {Ser307 }}$ phosphorylation [12]. In contrast, work in hepatic tissues suggest that protein kinase $C$ delta (PKCd) alters liver insulin signaling [13]. Focusing on the retina, studies have shown altered insulin signaling in the STZ model of type 1 diabetes [14]. In the STZ model, PKC altered insulin receptor immunoreactivity and signaling in endothelial cells and pericytes [14]. Additionally, work in the STZ model showed that insulin receptor signaling is key to health of the retinal pigmented epithelial (RPE) cells, leading to proper photoreceptor function [15].

Our findings in the present study suggest that retinal insulin signaling in impaired in the $\mathrm{db} / \mathrm{db}$ mouse. The findings of increased TNF $\alpha$ levels associated with increased IRS-1 Ser307 phosphorylation suggest that this may be the causative factor in the increased cleavage of caspase 3 . It is established that the $\mathrm{db} / \mathrm{db}$ mouse has altered retinal inflammation, which likely involves TNF $\alpha$ [6]. Increased TNF $\alpha$ can impair normal insulin signaling. Thus, retinal insulin signal transduction is impaired in the $\mathrm{db} / \mathrm{db}$ mouse, similar to other models of diabetes.

\section{References:}

1. Jiang $Y$, Zhang Q, Soderland C, Steinle JJ. TNFalpha and SOCS3 regulate IRS-1 to increase retinal endothelial cell apoptosis. Cell Signal. 2012;24(5):1086-92. Epub 2012/01/24. doi: 10.1016/j.cellsig.2012.01.003. PubMed PMID: 9393.

2. Jiang Y, Thakran S, Bheemreddy R, Ye EA, He H, Walker RJ, et al. Pioglitazone normalizes insulin signaling in the diabetic rat retina through reduction in tumor necrosis factor alpha and suppressor of cytokine signaling 3. The Journal of biological chemistry. 2014:26395405. doi: 10.1074/jbc.M114.583880. PubMed PMID: 9662. 
3. Jiang Y, Thakran S, Bheemreddy R, Coppess W, Walker RJ, Steinle JJ. Sodium salicylate reduced insulin resistance in the retina of a type 2 diabetic rat model. PloS one. 2015;10(4):e0125505. doi: 10.1371/journal.pone.0125505. PubMed PMID: 25874611; PubMed Central PMCID: PMCPMC4397086.

4. Beli E, Yan Y, Moldovan L, Vieira CP, Gao R, Duan Y, et al. Restructuring of the Gut Microbiome by Intermittent Fasting Prevents Retinopathy and Prolongs Survival in db/db Mice. Diabetes. 2018;67(9):1867-79. Epub 2018/05/02. doi: 10.2337/db18-0158. PubMed PMID: 29712667; PubMed Central PMCID: PMCPMC6110320.

5. Beli E, Prabakaran S, Krishnan P, Evans-Molina C, Grant MB. Loss of Diurnal Oscillatory Rhythms in Gut Microbiota Correlates with Changes in Circulating Metabolites in Type 2 Diabetic db/db Mice. Nutrients. 2019;11(10). Epub 2019/10/02. doi: 10.3390/nu11102310. PubMed PMID: 31569518.

6. Li W, Ma N, Liu MX, Ye BJ, Li YJ, Hu HY, et al. C1q/TNF-related protein-9 attenuates retinal inflammation and protects blood-retinal barrier in $\mathrm{db} / \mathrm{db}$ mice. Eur J Pharmacol. 2019;853:289-98. Epub 2019/04/13. doi: 10.1016/j.ejphar.2019.04.012. PubMed PMID: 30978318.

7. Ying Y, Zhang YL, Ma CJ, Li MQ, Tang CY, Yang YF, et al. Neuroprotective Effects of Ginsenoside Rg1 against Hyperphosphorylated Tau-Induced Diabetic Retinal

Neurodegeneration via Activation of IRS-1/Akt/GSK3beta Signaling. J Agric Food Chem. 2019;67(30):8348-60. Epub 2019/07/16. doi: 10.1021/acs.jafc.9b02954. PubMed PMID: 31304751.

8. Jiang Y, Pagadala J, Miller D, Steinle JJ. Reduced insulin receptor signaling in retinal Muller cells cultured in high glucose. Molecular vision. 2013;19:804-11. PubMed PMID: 9512; PubMed Central PMCID: PMC3626298.

9. Liu L, Steinle JJ. Toll-like receptor 4 regulates insulin signal transduction in retinal Muller cells. Growth Factors. 2017;35(6):234-8. doi: 10.1080/08977194.2018.1442833. PubMed PMID: 29490521; PubMed Central PMCID: PMCPMC5948174.

10. Jiang $\mathrm{Y}$, Liu L, Steinle JJ. miRNA15a regulates insulin signal transduction in the retinal vasculature. Cell Signal. 2018. doi: 10.1016/j.cellsig.2018.01.016. PubMed PMID: 29339083. 11. Salinari S, Debard C, Bertuzzi A, Durand C, Zimmet P, Vidal H, et al. Jejunal proteins secreted by $\mathrm{db} / \mathrm{db}$ mice or insulin-resistant humans impair the insulin signaling and determine insulin resistance. PloS one. 2013;8(2):e56258. Epub 2013/02/26. doi:

10.1371/journal.pone.0056258. PubMed PMID: 23437106; PubMed Central PMCID: PMCPMC3577828.

12. Shen Q, Cline GW, Shulman GI, Leibowitz MD, Davies PJ. Effects of rexinoids on glucose transport and insulin-mediated signaling in skeletal muscles of diabetic $(\mathrm{db} / \mathrm{db})$ mice. The Journal of biological chemistry. 2004;279(19):19721-31. Epub 2004/03/05. doi: 10.1074/jbc.M311729200. PubMed PMID: 14998989.

13. Zhang J, Burrington CM, Davenport SK, Johnson AK, Horsman MJ, Chowdhry S, et al. PKCdelta regulates hepatic triglyceride accumulation and insulin signaling in Lepr(db/db) mice. Biochemical and biophysical research communications. 2014;450(4):1619-25. Epub 2014/07/19. doi: 10.1016/j.bbrc.2014.07.048. PubMed PMID: 25035929.

14. Kida T, Oku H, Horie T, Osuka S, Fukumoto M, Ikeda T. Protein kinase C-mediated insulin receptor phosphorylation in diabetic rat retina. Graefes Arch Clin Exp Ophthalmol. 2019;257(7):1427-34. Epub 2019/04/27. doi: 10.1007/s00417-019-04324-z. PubMed PMID: 31025213.

15. Tarchick MJ, Cutler AH, Trobenter TD, Kozlowski MR, Makowski ER, Holoman N, et al. Endogenous insulin signaling in the RPE contributes to the maintenance of rod photoreceptor function in diabetes. Experimental eye research. 2019;180:63-74. Epub 2018/12/14. doi: 10.1016/j.exer.2018.11.020. PubMed PMID: 30543793; PubMed Central PMCID: PMCPMC6389378. 


\section{Figure Legends:}

Figure 1. Western blotting for insulin receptor $(A)$ and Akt phosphorylation $(B)$ in $\mathrm{db} /+($ Control) and $\mathrm{db} / \mathrm{db}$ mouse retinal lysates. ${ }^{*} \mathrm{P}<0.05$ vs. Control. Data are mean \pm SEM. $\quad \mathrm{N}=5$.

Figure 2. Western blotting for TNF $\alpha(A)$ and IRS-1 ${ }^{\text {Ser307 }}$ phosphorylation in $\mathrm{db} /+($ Control) and $\mathrm{db} / \mathrm{db}$ mouse retinal lysates. ${ }^{*} \mathrm{P}<0.05$ vs. Control. Data are mean \pm SEM. $\quad \mathrm{N}=5$.

Figure 3. ELISA results for cleaved caspase $3 \mathrm{in} \mathrm{db} /+$ (Control) and $\mathrm{db} / \mathrm{db}$ mouse retinal lysates. ${ }^{*} \mathrm{P}<0.05$ vs. Control. Data are mean \pm SEM. $\quad \mathrm{N}=5$. 


\begin{tabular}{|l|l|l|}
\hline & Body weight $(\mathrm{g})$ & $\begin{array}{l}\text { Blood glucose } \\
(\mathrm{mg} / \mathrm{dl})\end{array}$ \\
\hline $\mathrm{Db} /+$ & 21.6 & 118 \\
\hline $\mathrm{Db} / \mathrm{db}$ & $>60^{*}$ & $>600^{\star}$ \\
\hline
\end{tabular}

Table 1. Body weight $(\mathrm{g})$ and blood glucose $(\mathrm{mg} / \mathrm{dl})$ of $\mathrm{db} /+($ Control) and $\mathrm{db} / \mathrm{db}$ mice at sacrifice. ${ }^{*} \mathrm{P}<0.05 \mathrm{vs} . \mathrm{db} /+. \quad \mathrm{N}=5$. 
Figure 1

A.

B.

$$
\text { p-IR }
$$

IR

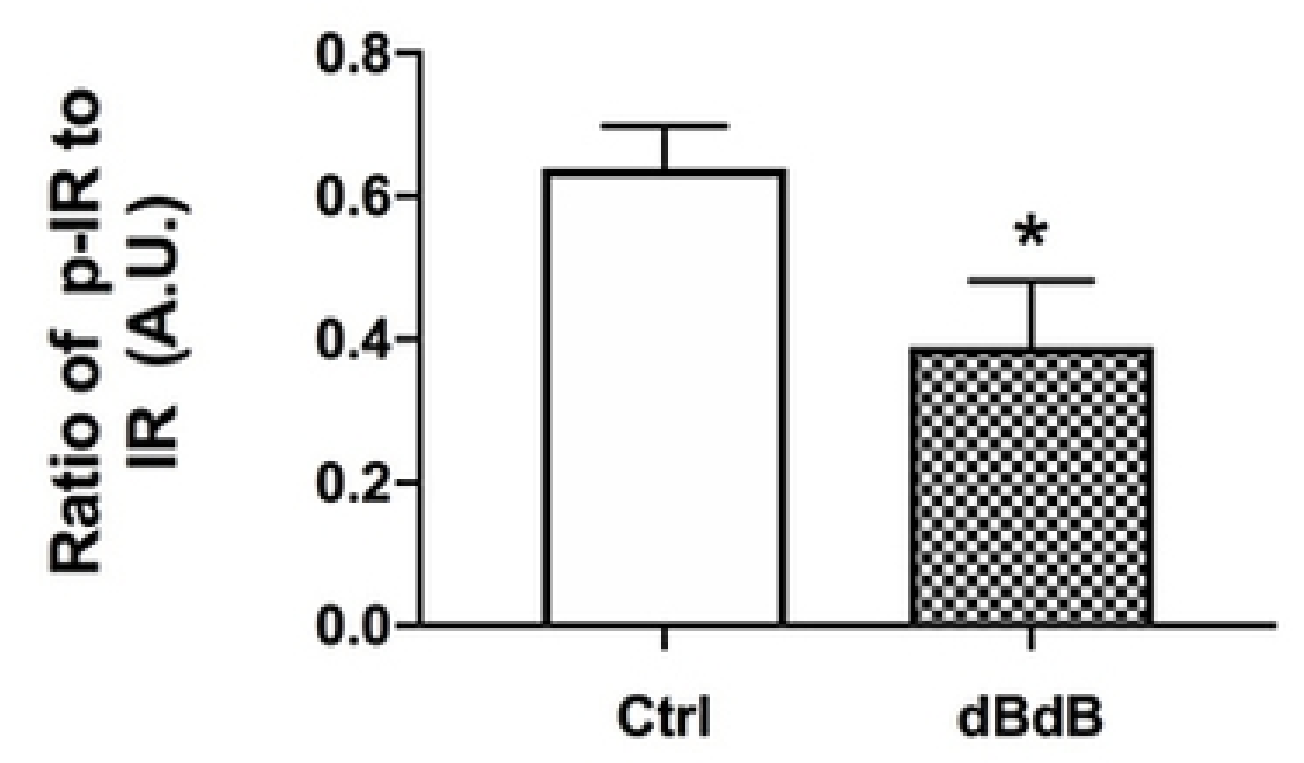

p-Akt

Akt

Figure 1

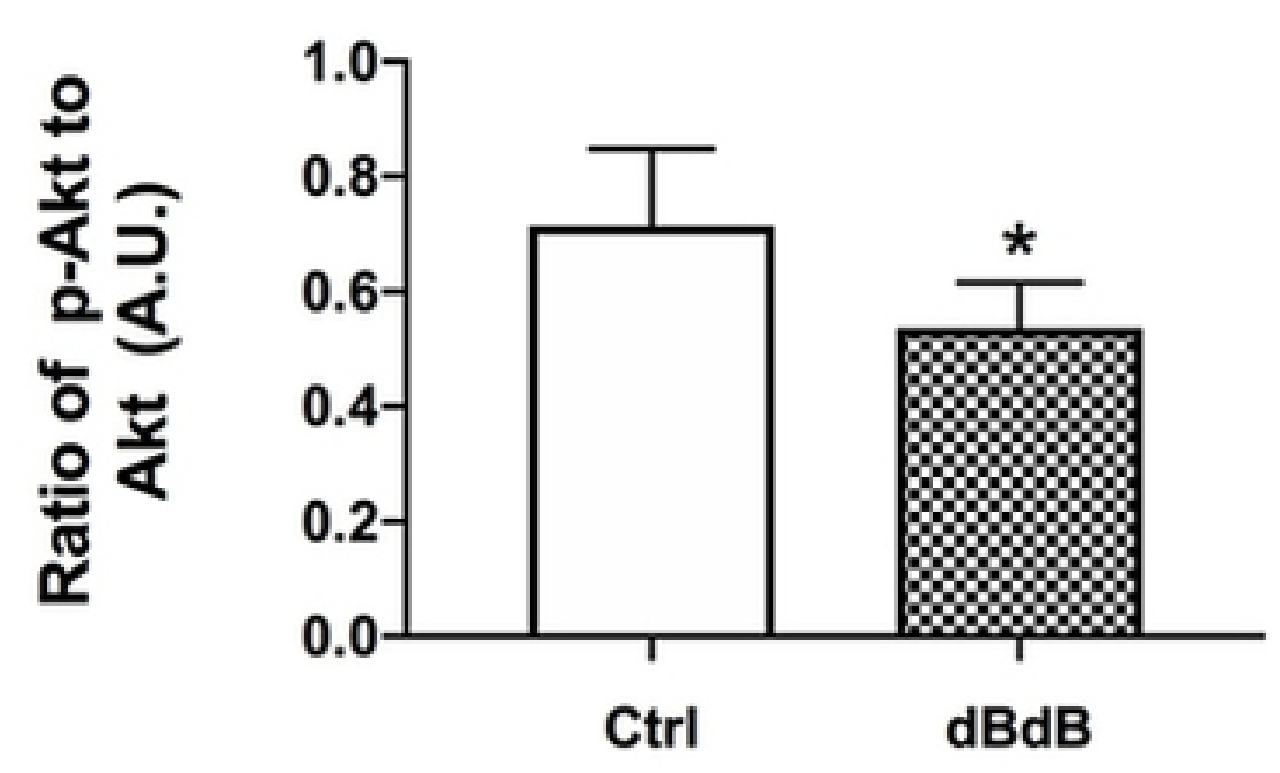


Figure 2

A.

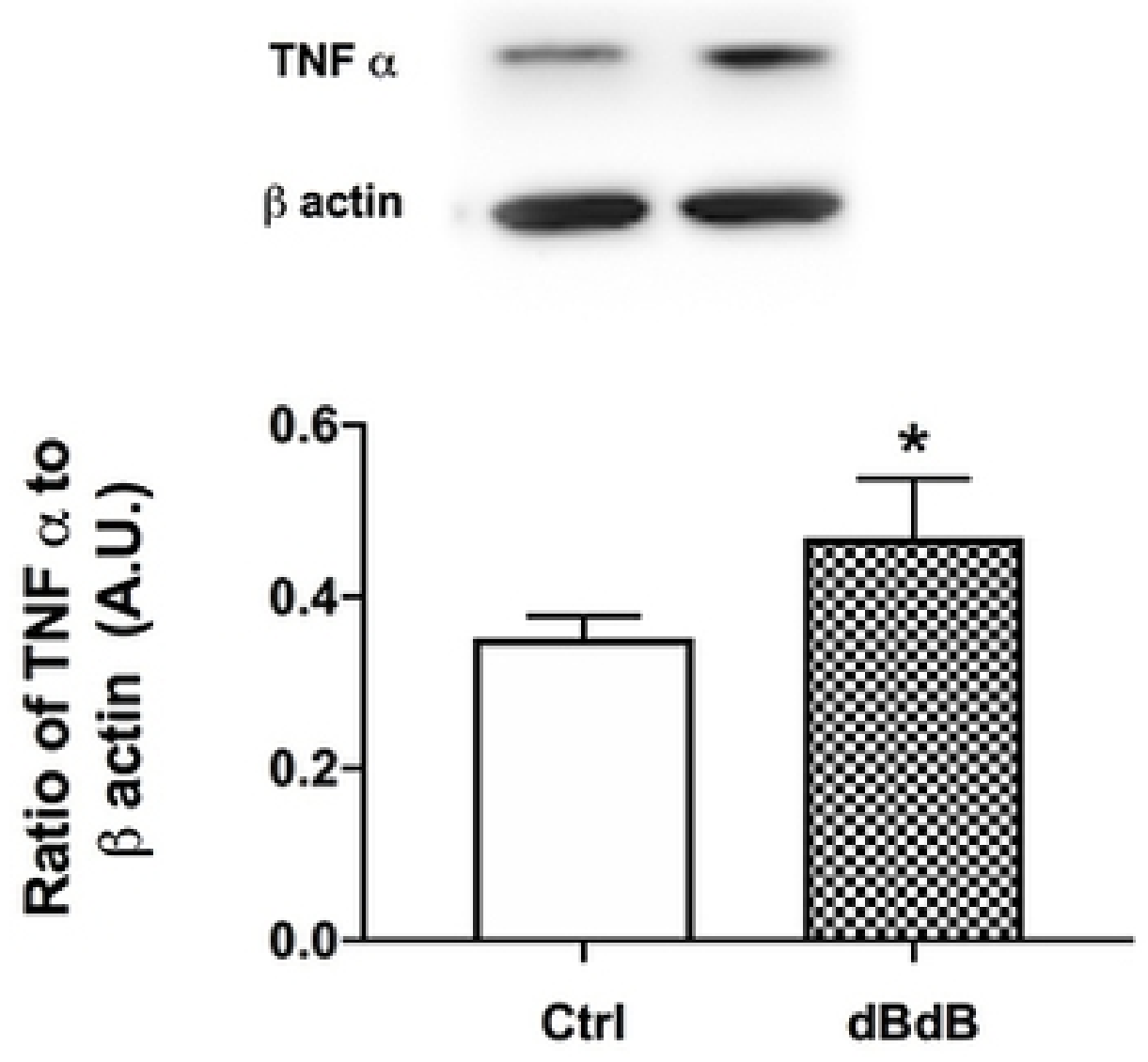

B.

$$
\text { p-IRS1 }
$$

IRS1

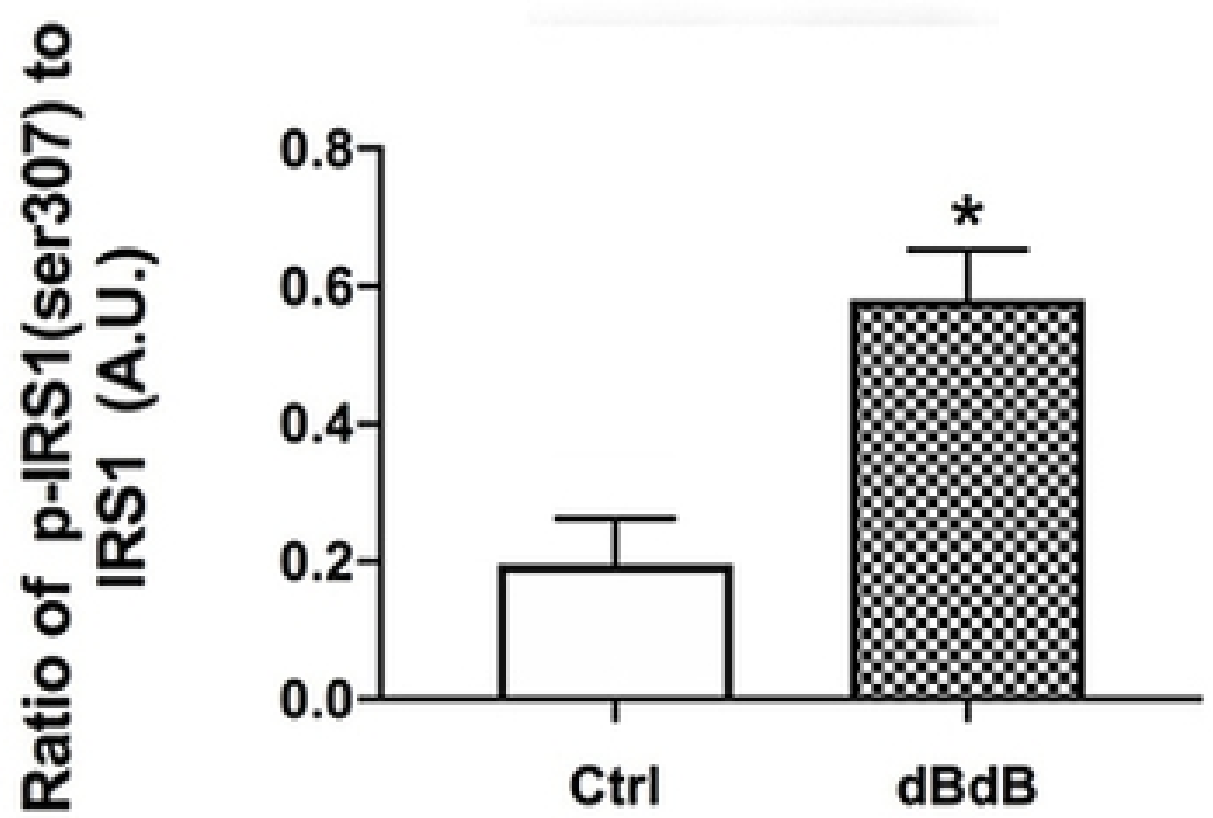

Figure 2 


\section{Figure 3}
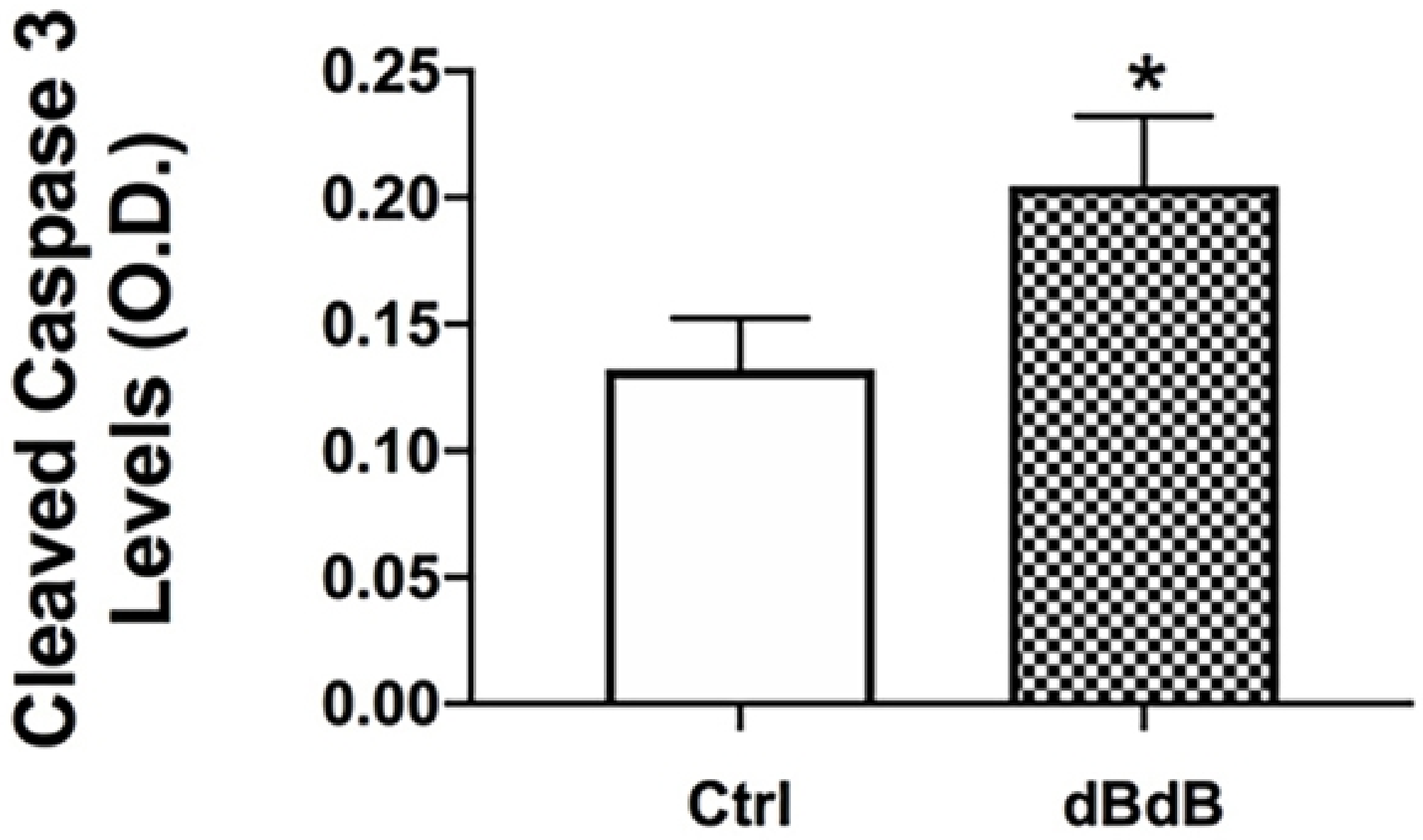

Figure 3 